\title{
Endoscopic resection of a giant ileal inflammatory fibroid polyp by retrograde double-balloon enteros- copy
}

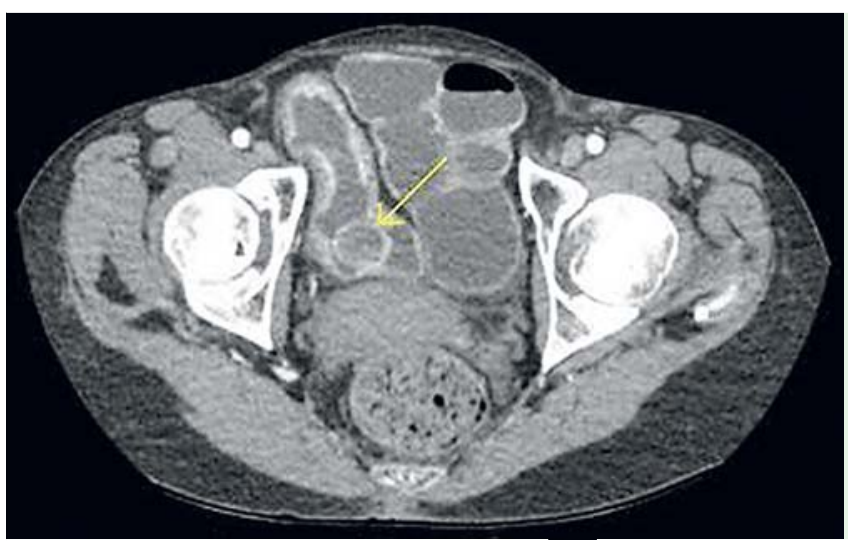

Fig. 1 Axial computed tomography enterography (CTE) image showing a polypoid lesion (arrow) projecting into the lumen of the distal ileum, the mucosa of which shows contrast hyperenhancement, consistent with inflammation.

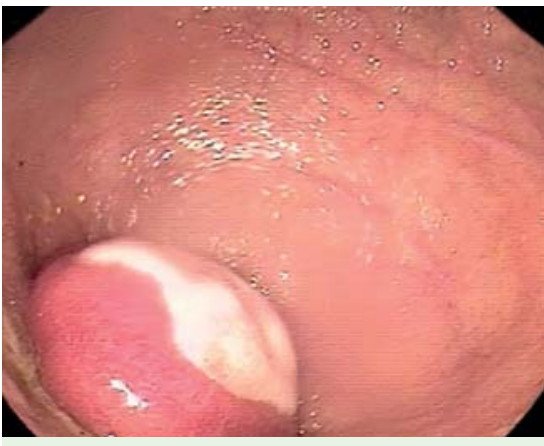

Fig. 2 View during retrograde double-balloon enteroscopy (DBE) showing a large polypoid lesion in the distal ileum with an overlying cap of necroinflammatory exudate.

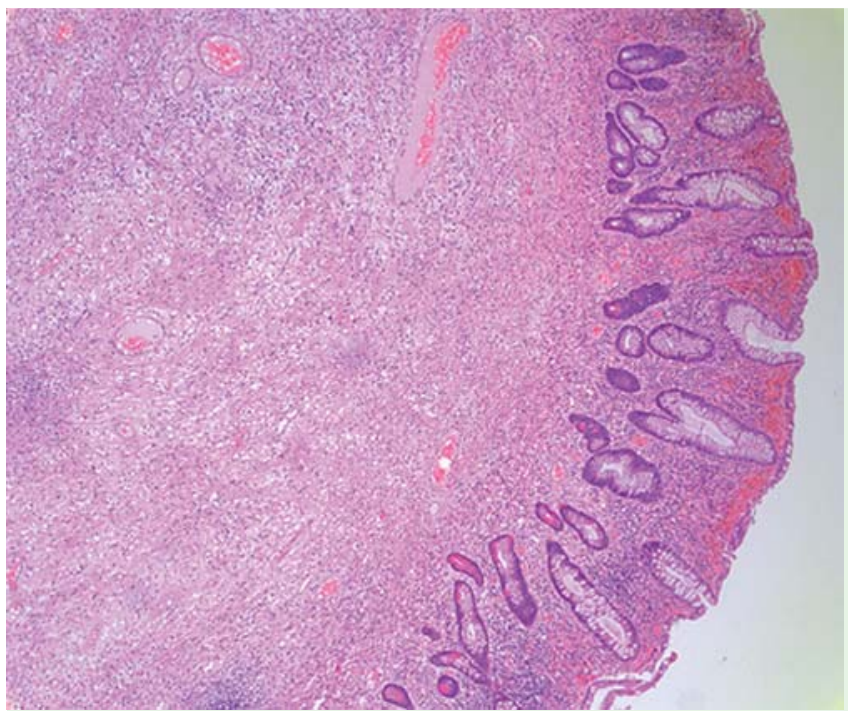

Fig. 4 Histopathological appearance of the hematoxylin and eosin (H\&E)-stained excised submucosal lesion, which consisted of sparsely cellular proliferating spindle cells set within an edematous stroma containing small and large vessels and an inflammatory cell infiltrate that was rich in eosinophils (magnification $\times 10$ ).
A 70-year-old woman with a longstanding history of ileocolonic Crohn's disease was reviewed in our inflammatory bowel disease clinic. Although her Crohn's diseaserelated symptoms were well controlled on azathioprine and 5-aminosalicylic acid therapy, computed tomography enterography (CTE) demonstrated active disease affecting the distal ileum and right colon with an ileal polyp that had increased in size from $14 \mathrm{~mm}$ to $30 \mathrm{~mm}$ over a 2-year follow-up period ( $\bullet$ Fig. 1 ). Histopathology of biopsies taken from the distal ileal polyp were consistent with an inflammatory etiology but, because of its increasing size and the risk of intussusception, the lesion was deemed to merit endoscopic excision.

Retrograde double-balloon enteroscopy (DBE) identified the ulcerated polypoid lesion located within a segment of severely active Crohn's disease that was affecting the last $40 \mathrm{~cm}$ of the terminal ileum ( $\nabla$ Fig. 2). The head of the polyp was injected with a $1: 10000$ epinephrine solution to reduce its size and bleeding risk [1]. The lesion was then removed by en bloc endoscopic mucosal resection ( $\bullet$ Fig.3). Histopathological examination confirmed complete excision of a submucosal lesion composed of sparsely cellular proliferating spindle cells, set within an edematous stroma containing small and large vessels and inflammatory cell infiltrate rich in eosinophils ( $\bullet$ Fig.4), consistent with an inflammatory fibroid polyp (IFP).

IFPs are rare benign submucosal lesions which, although they may arise anywhere within the gastrointestinal tract, affect the small bowel in only $18 \%$ of cases [2]. Intussusception, obstruction, and bleeding are recognized complications of small-bowel IFPs [3]. Simultaneous occurrence of active Crohn's disease with such lesions has rarely been described, and it has been proposed that disease activity may be the local stimulus for the formation of this apparently reactive lesion [4]. To the best of our knowledge, this is the largest small-bowel IFP (and only the third such case) to be resected by balloon-assisted enteroscopy $[2,5]$.

Endoscopy_UCTN_Code_TTT_1AP_2AD

Competing interests: None

Faidon-Marios Laskaratos ${ }^{1}$, Erasmia Vlachou ${ }^{1}$, Tu Vinh Luong ${ }^{2}$, Peter Wylie $^{3}$, Mark I. Hamilton ${ }^{4}$, Charles D. Murray ${ }^{4}$, Edward J. Despott ${ }^{1}$

Royal Free Unit for Endoscopy, Royal Free London NHS Foundation Trust, London, UK

${ }^{2}$ Academic Department of Cellular Pathology, Royal Free London NHS Foundation Trust, London, UK ${ }^{3}$ Radiology Department, Royal Free London NHS Foundation Trust, London, UK ${ }^{4}$ Inflammatory Bowel Disease Unit, Royal Free London NHS Foundation Trust, London, UK 


\section{References}

1 Hogan RB, Hogan RB 3rd. Epinephrine volume reduction of giant colon polyps facilitates endoscopic assessment and removal. Gastrointest Endosc 2007; 66: 1018-1022

2 Mohamud S, Motorwala S, Daniel $R$ et al. Giant ileal inflammatory fibroid polyp causing small bowel obstruction: a case report and review of the literature. Cases Journal 2008; 1 : 341

3 Yoon DW, Lee BJ, Lee JH et al. A case of giant inflammatory ileal polyp removed by double-balloon enteroscopy. Clin Endosc 2012; 45: $198-201$
4 Deschamps L, Bretagnol F, Couvelard A et al. Inflammatory fibroid polyp in Crohn's disease revealed by ileo-ileal intussusception: case report and review of the literature. Inflamm Bowel Dis 2008; 14: 1317-1320

5 Wolff J, Twaddell W, Darwin P. Endoscopic resection of an ileal inflammatory fibroid polyp using retrograde single balloon enteroscopy. Clin Gastroenterol Hepatol 2009; 7: e66-e67

\section{Bibliography}

DOI http://dx.doi.org/

10.1055/s-0035-1569649

Endoscopy 2016; 48: E14-E15

(C) Georg Thieme Verlag KG

Stuttgart · New York

ISSN 0013-726X

\section{Corresponding author \\ Edward J. Despott, MD}

Royal Free Unit for Endoscopy

8th Floor, South Offices

Royal Free Centre for Gastroenterology and UCL Institute for Liver and Digestive Health,

Royal Free London NHS Foundation Trust London

NW3 2QG

United Kingdom

edespott@doctors.org.uk 